\title{
Sowing New Foundations: Refugee and Immigrant Women and Support Groups
}

\author{
Helene Moussa
}

This paper discusses issues related to the settlement process of women refugees and their families. The issues emerged from an Education Wife Assault (EWA) project which set out to produce a handbook to assist refugee and immigrant women in establishing support groups. Drawing on the experience of support group facilitators, guidelines and descriptions of group approaches to domestic violence were drawn up (Moussa 1994). A major theme that cut across the work of these facilitators was that of refugee/immigrant women challenging myths about themselves and society, and claiming power both individually and in solidarity with each other.

Fifty-five group facilitators in Metropolitan Toronto, Kitchener and Hamilton were interviewed for the project. Some of the facilitators worked with specific country/language groups and others with multi-ethnic and multilingual groups. Facilitators for the specific country/language groups worked with women from China, Ethiopia, Eritrea, Philippines, Ghana, Iran, Korea, Portuguesespeaking countries, Somalia and Sri Lanka. The various groups met in community centres, agencies and shelters for assaulted women.

Support groups are one of the many ways of breaking the isolation women experience in the settlement process. In a group, women learn how to access the social, economic, political and legal systems of Canada. The strengths, skills and talents of each woman are validated.

The concept of a "support group" is a Western one and not necessarily applicable to the cultural background

Helene Moussa is a research associate at CRS. Her book Storm and Sanctuary: The Journey of Ethiopian and Eritrean Women Refugees was published in 1993 (ISBN 1895247-08-x). and realities of refugee/immigrant women in Canadian society. Women in many parts of the world relate to one another in woman-centred groups within the neighbourhood or extended family.

The objectives of the support groups were multifaceted. Topics covered fell into four broad categories: life skills in Canada; information about how to access services; social activities and recreation; and the politics of sexual violence within the context of being a refugee or immigrant woman.

This article focuses on four interrelated issues drawn from the discussions with facilitators: (1) the need for an integrated response to refugee and immigrant families; (2) concerns about cultural perceptions; (3) the importance of respecting cultural differences and recognizing structural barriers in the settlement process; and (4) how the support group experience can become a springboard for refugee/immigrant women to claim power over their lives.

\section{The Need for an Integrated \\ Response to Immigrant and Refugee Families}

The most important concern that came across when working with refugee and immigrant women was the fragmentation of services to the family. Facilitators expressed the need for an integrated approach which coordinated services to the family as a "unit."

"Keeping the family together" has particular significance for refugee women. Mothers, fathers and children may have been separated from each other when they fled their country. Refugee/immigrant women experience isolation because the public/private divide in Canadian society is unfamiliar to them. Racism and hostility toward refugees/immigrants create additional layers of alienation for newcomers during the settlement process. Furthermore, each refugee in his or her own way, goes through a period of grievance over the separation from family and country of origin. In addition, women are generally held responsible for "holding the family together" during the settlement process. One of the implications of all these factors is that women may remain in relationships, even when those relationships are abusive or life-threatening.

Responses to the needs of women must address both the family as a unit and each of its members. An integrated response recognizes the political context of the lives of refugee/immigrant women. As Alice Walker argues, "a womanist approach" is a commitment to the survival and wholeness of entire communities, including both female and male members (Walker 1983, ix).

\section{Child and Youth "Care"}

Child care is an essential component of any service to immigrant/refugee mothers. Mothers will not, and cannot, attend group sessions if such care is not provided. Support group facilitators stressed that child care should not be limited to "baby-sitting." Children and youth have special needs, particularly as "hidden victims" of family violence.

Children in refugee families may have been imprisoned and tortured. They may have been in situations of armed conflict. They may have witnessed the torture and death of a parent(s) and family member(s). They may have been separated from one or both of their parents because of any or all of these reasons. Children in refugee and immigrant families may also experience racism in schools and the various stresses of settlement. Children respond to trauma in ways that are very different from those of adults and must be cared for in the context of 
their development (Freire 1989; Amnesty International 1990; McCallin 1993).

Settlement pressures such as unemployment or underemployment, language barriers, racism and sexism often demand so much of parents' time and emotion that their children's needs may be of secondary importance. Mothers do not need more fracturing of the family or further isolation added to this situation. Support groups for mothers can help them associate dysfunctional behaviour in their children, such as withdrawal, aggression, and poor performance in school, to the violence they may have witnessed both prior to coming to Canada and within Canada.

Facilitators reported that the difficulties many mothers experience with teenage children is perhaps one of the biggest gaps to be bridged. The values that teens acquire from peers and the media can create friction between them and their parents. Facilitators said that mothers were often "at the end of their wits" about what to do, and many felt "totally powerless." The challenge, a facilitator said, is to find ways we can reach teenagers because they will not readily attend a support group.

Facilitators were exploring culturespecific ways of responding to children's needs. For example, a Caribbean community wife assault project is matching children with families known to have healthy relationships. Children visit these families and are included in some family activities. It is hoped that when children are exposed to nonviolent behaviour and positive role models, they will learn alternative ways of resolving conflicts. The interesting thing about this experiment is that in many cultures it is not unusual for a child to spend time with an extended family member or even a neighbour.

\section{What Help Do Men Need as Part of Meeting Women's Needs?}

Understanding violence against women in refugee and immigrant families requires consideration of how male power is constructed in their country of origin and subsequently deconstructed by the refugee experience and settlement in Canada. This does not mean that male violence is condoned or excused. Rather, it challenges us to unravel the context in which violence occurs and this in turn should help us to better respond to the protection needs of women. These factors also help us understand the barriers women have to overcome before they will speak out and take action against an abusive relationship.

Fear and distrust of authority figures is particularly strong among refugees who may have experienced torture and other forms of state violence.

A woman is also unlikely to report her abusive partner to the police when it was the police in her home country who tortured her and/or her family. parts of the world, marriage is not a simple union between an individual man and a woman, it is also a union of their extended families. Separation and divorce, therefore have wider implications than the couple per se. An abusive man may use this tradition as a tool to control the situation further.

Facilitators claimed that groups for men can be one of social spaces in which men learn about the construction of male power and the abuse of such power. Such groups should start early in the settlement process so that men can learn different, healthy ways of dealing with the frustration and humiliation of the settlement process.

\section{Public Education}

Support groups for women and children, and men's groups will remain isolated in their effects to change gender power relations if they are not sup-

\section{...[I]n many parts of the world, marriage is not a simple union between an individual man and a woman, it is also a union of their extended families. Separation and divorce, therefore have wider implications than the couple per se. An abusive man may use this tradition as a tool to control the situation further.}

The growing hostilities toward refugees and immigrants and other forms of racism make it even harder to break this silence. A community worker in Toronto said that battered women will choose solidarity with their ethno-specific community rather than seek personal safety in the belief that exposing male violence reinforces racist stereotypes that their community consists of ruthless terrorists. This community worker was not condoning the women's choice, merely pointing out a barrier that had to be faced.

Women experience additional barriers; for example, family members may, for a wide range of reasons, collude to prevent women from reporting violence inflicted upon them. Family members may also blame the woman for her victimization. If women are sponsored by in-laws, this reinforces dependency and intensifies the fear of taking action. In addition, in many plemented with public education. One of the mandates of the Coalition to Eradicate Violence against Women and Children in the Spanish-Speaking Community (Toronto), is to carry out public education and training activities on this issue. The creation of this coalition is itself a statement from and to the Spanish-speaking community that violence against women and children is unacceptable.

\section{Funding}

To achieve an integrated approach, facilitators argued that it is necessary to convince funding and collaborative agencies that their approaches and criteria have to accommodate the specific reality of refugee and immigrant women.

\section{Culture Specific Approaches}

Regardless of our background, we look at other cultures through the lens 
of our own culture. The difficult question is, "how can we cross this cultural bridge to be able to respond to those who are 'different' from us?"

The concept of "cultural sensitivity" is often used in Canada as a way of relating in a positive manner to the cultural background of newcomers. "Sensitivity" alone can, however, be a patronizing, if not incomplete, response to social and political situations. "Sensitivity" is a psychological response, and as such, is only a partial strategy; whereas, culture is also political and ideological. Professionals have to recognize the ideological filters of their own cultural lenses and the dominant culture.

A further concern about the term "cultural sensitivity" is that it does not reflect the two-way process of cultural exchange, nor does it acknowledge that refugee and immigrant women have a great deal to offer Canadian society. The facilitators emphatically affirmed that the support groups reinforced the rich heritage of relationships and mutual support among the women; a heritage which the West has lost as a result of highly individualistic values which engender alienation. One of the facilitators said:

We need to continue to find ways of re-inventing our social and relationship values in Canada alongside with life-giving values in Canadian society. This heritage is not often visible or tangible-it is how we live and how we relate to each other, including the ways we can resolve our issues.

Another important role of a support group facilitator is to "interpret" Canadian society from the immigrant/ refugee perspective. Many facilitators said that they openly shared their personal struggles with women in the group, including experiences with sexual assault, abuse and accomplishments in the settlement process.

Carrying this notion of mutual cultural change further, facilitators who are not members of "minority" ethnospecific groups need to question their own cultural myths and beliefs, as well as their privileged positions. This re- quires an openness toward learning from other cultures. Refugees may themselves be able to offer different approaches to the "Canadian way" of responding to wife assault-even outside their own ethnocultural communities!

To feel valued, immigrant and refugee women must also feel respected as contributing members of the Canadian economic, cultural, political and social systems. They need to be in control of important life choices and decisions. They need to be seen as actively shaping their personal and collective lives, rather than depending on others and institutions.

\section{Respecting Cultural Differences and Recognizing Structural Barriers}

A starting point, it would seem, is respecting cultural differences and recognizing that refugee women are not in a position of power in Canada because of pervasive racism, existing class structures, sexism and gender inequality. Searching for commonalities in our effort to bridge the gaps is important, but not enough. Identifying commonalities must not be confused with "sameness" because this overlooks the structural barriers within Canadian society which prevent refugee and immigrant women from participating equally in Canadian society. Racism blinds people from understanding the cultural norms and beliefs of people who are "different." Cultural differences can be manifested in derogatory, stereotypical and misinformed beliefs. Popular images of Islam and Muslims, for instance, generally fail to indicate that the Qur' an (not unlike the Holy Bible) has many contemporary interpretations of the status of women, among other social issues (Ahmed 1992; Zuhur 1992; Moghadam 1993). There is also ample evidence in the literature on the intersection of race, class and gender barriers in the lives of immigrant women ( $\mathrm{Ng} \mathrm{1988;} \mathrm{Vorst} \mathrm{1989;}$ Bannergi 1993).

Refugee and immigrant women are not a homogenous group even though their experiences in Canada are simi- larly constructed by legal, economic and social systems. They come from different classes and backgrounds. Educational background, for example, varies according to the level of education attained, when and where school was attended, and the historical context.

While the majority of immigrant and refugee women enter Canada in the "sponsored" or "spouse" immigration categories, many come independently. In a situation involving wife assault, different questions and strategies should be considered for each of the following situations: when both the man and the woman are awaiting decision of their refugee claim; when a woman is sponsored and arrives in Canada with her husband/family; when a woman is sponsored and follows her husband/family at a later date (sometimes several years later); when a woman comes to Canada without her spouse or ahead of him; when a woman comes to Canada ahead of her children; and when a woman arrives in Canada independent of her current relationship.

All of the support group facilitators emphasized that we must look for the less visible, inner strength of women. Women, we know, are resourceful and able to make decisions. Women are not "helpless." Refugee women, for instance, make a major decision when they flee their country. Some may have never travelled unaccompanied within their country, let alone abroad. For many, the decision to flee is an act of resistance to patriarchal traditions and state repression.

While there may appear to be common patterns in wife/sexual assault experiences, the literature and experience of women from the South points out that there is no universal way of responding to women in abusive relationships (Ghandi and Shah 1992; Centre for Women's Global Leadership 1992; Schuler 1992; CLAMDEM 1993). Facilitators emphasized that it was critically important to acknowledge and apply different and relevant ways of assisting refugee/immigrant women in abusive relationships. 
The Western notion, for instance, that sharing an experience of violence can be cathartic is not necessarily valid, particularly when it is with a stranger who does not speak your language. A refugee woman who is assaulted by her partner may also have been tortured, fled, and subsequently raped in a refugee camp. How do these experiences of sexual assault affect her decision making? Has she processed the experience of torture or rape? What are the legal and economic pressures she has to contend with? What are the social pressures she is experiencing from members of her extended family and the community?

Not sharing all or any of these experience does not necessarily mean that women are passive or submissive. They may be struggling to cope with a multitude of barriers. They may want to forget the traumatic experiences of separation from family, death and war.

Submissiveness to authority may also have political, rather than genderbased, or cultural explanations. Challenging authority in a repressive political regime can result in imprisonment. Such fears will not magically disappear just because a refugee woman has set foot in Canada. In fact, racism in Canada does not nurture trust or resolve their legitimate fear and distrust of authority figures. The image of the police and the criminal justice system as "protectors" is not part of their life experience.

In Canada, assertive behaviour is highly valued and it is sometimes exhibited in ways which some cultures perceive as rather impolite, if not downright rude. In a letter to a friend, a South Asian woman identified a number of differences in perspectives and values in her culture from those of her Western friend. One of her examples, highlights the difference in values related to assertive behaviour, "If you saw the film Gandhi you may have seen a few glimpses of being effective without being assertive in the North American way" (Cairncross 1989, 83). This woman is also pointing out that women may resist oppression in very different ways.

When refugees flee their homes and countries, sometimes culture is all that they have left of their identities. Refugees and immigrants often cling to familiar ways so as not to feel totally disempowered. This is a way of establishing continuity in their lives when so much has been fractured. The task, facilitators said, is to find ways for women to retain values that are lifegiving and learn to let go of values that are not life-giving.

Respecting and recognizing differences does not mean condoning cultural beliefs which effectively sanction the oppression of women. Rather, it involves considering different and cul-

identities other than mere "survivors." In fact, for some, surviving can create guilt: she has survived when many others have not. Women have many other identities: as members of national and ethnic groups, and as workers, professionals, artists, care-givers and activists. These identities have to be named, nourished and encouraged if women are to claim power over their lives.

Since the life-span of a support group is generally three to six months, facilitators stressed the importance of planning ways in which they can continue to build support systems and network with other women. The effec-

\section{When refugees flee their homes and countries, sometimes culture is all that they have left of their identities. Refugees and immigrants often cling to familiar ways so as not to feel totally disempowered.}

turally appropriate ways of working through such issues as violence against women. Challenging the myths women have learned from their own patriarchal societies is an important part of support group activities and the settlement process. Support group activities explore and question cultural values, practices and myths that are not life-giving or that may hurt, harm and oppress women. Many Somali women, for instance, are educating women in their community about the detrimental emotional and health effects of the practice of female genital mutilation. They are also challenging the doctrine that this practice is fundamental to their religious beliefs. Recognizing and respecting difference requires conscientious dedication and perseverance.

\section{Moving from Victim to Survivor to Advocate and Networking}

An essential component of support groups is the encouragement of women to overcome attitudes identifying them as "victims" and "survivors." Violence against women is systemically and ideologically embedded in patriarchal gender relations. To claim power over their lives, women have to acknowledge that they have tiveness of a support group is in part measured by the ability of its participants to develop their own networks. As one support group facilitator said:

If there is no follow-up plan it's like abandoning the women after you have given them a chance to experience something meaningful and enjoyable in their lives.

Follow-up can take shape in many different ways: one group of Somali women organized families in their housing project. They learned about their rights as tenants and how to generate solutions to the issues they were facing with overcrowding. They are also planning on setting up a transition housing project for women who leave abusive relationships.

Support group facilitators often invite women who have attended previous groups to speak to newly formed groups about their struggles and accomplishments, and how, as members of a support group, they can make it work for their needs.

\section{References}

Ahmed, Leila. 1992. Women and Gender in Islam: Historical Roots of a Modern Debate. New Haven: Yale University Press.

Amnesty International. 1990. "Children - the Youngest Victims." In Victims of Human Rights Violations. Washington. 